\title{
Nilai- nilai Pendidikan Karakter dalam Pengelolaan Pelayanan Musik pada IFGF Praise Manado
}

\author{
${ }^{1}$ Victor Pieter, ${ }^{2}$ Markus Wibowo, ${ }^{3}$ Erwin Sianturi \\ Institut Agama Kristen Negeri Manado
}

\author{
11victorpieter98@gmail.com, 2wibowomarkus96@gmail.com, 33kacamataerwin@gmail.com
}

\begin{abstract}
Abstrak
Penelitian ini bertujuan untuk mengkaji nilai-nilai pendidikan karakter dalam pengelolaan pelayanan musik pada IFGF Praise Manado. Metode yang digunakan adalah metode Kualitatif dengan pendekatan Studi Kasus.Konsep dasar pengelolaan pelayanan musik ini menggunakan teori manajemen George R. Terry yaitu ; perencanaan, pengorganisasian, penggerakan, dan pengawasan. Palam pelaksanaannya, pengelolaan pelayanan musik di IFGF Praise mengadopsi konsep-konsep manajemen pertunjukan yang dikemukakan oleh Jazuli dalam Majanemen Seni Pertunjukan. Konsep-konsep tersebut adalah sistem pelembagaan, program, tata kerja, siste, pembiayaan, pemasaran, dan tata penyelenggaraan program kegiatan. Dari hasil observasi dan pengumpulan data melalui wawancara dengan beberapa narasumber di IFGF Praise Manado dapat disimpulkan bahwa adanya relevansi konsep pengelolaan pelayanan musik menggunakan teori manajemen dan konsep-konsep dalam manajemen pertunjukan. Keberhasilan pelayanan tim IFGF Praise Manado merupakan hasil dari sinergi antara tim IFGF Praise dan tim The Box pada kegiatan yang dinamakan dengan Supersunday Servicedi IFGF Manado. Adanya pengelolaan yang baik, terstruktur dan terarah maka berdampak pada munculnya nilai-nilai pendidikan karakter pada anggota tim IFGF Praise dan tim The Box IFGF Manado. Nilai-nilai pendidikan karakter yang dimaksud adalah antara lain : Pendidikan Karakter Kepemimpinan, Pendidikan Karakter Spiritualitas, dan Pendidikan Karakter Peduli Sosial.
\end{abstract}

\section{Kata Kunci : Pengelolaan Pelayanan Musik, Pendidikan Karakter}

\begin{abstract}
This study aims to examine the values of character education in the management of music services at IFGF Praise Manado. The method used is a qualitative method with a case study approach. The basic concept of music service management uses George R. Terry's management theory, namely; planning, organizing, mobilizing, and controlling. In its implementation, the management of music services at IFGF Praise adopts the performance management concepts proposed by Jazuli in Majanemen Performing Arts. These concepts are the system of institutionalization, programs, work procedures, systems, financing, marketing, and the administration of program activities. From the results of observations and data collection through interviews with several resource persons at IFGF Praise Manado, it can be concluded that there is relevance to the concept of music service management using management theory and concepts in performance management. The success of the service of the IFGF Praise Manado team is the result of the synergy between the IFGF Praise team and The Box team in an activity called Supersunday Service at IFGF Manado.

The existence of good, structured and directed management has an impact on the emergence of character education values for members of the IFGF Praise team and the IFGF Manado The Box team. The values of character education in question are, among others: Leadership Character Education, Spirituality Character Education, and Social Care Character Education.
\end{abstract}

Keywords : Music Service Management, Character Education 


\section{Pendahuluan}

Kondisi perubahan zaman menuntut adanya pengelolaan dalam sebuah organisasi yang harus mengikuti perubahan zaman. Kondisi sekarang yang dikenal dengan zaman milenial menawarkan berbagai macam kemajuan baik didalam hal teknologi informasi, pendidikan dunia kesehatan, perdagagan dan perekonomian, bahkan dalam pengelolaan sebuah organisasi. Perubahan zaman berdampak pada globalisasi dan modernisasi. Modernisasi merupakan perubahan masyarakat tradisional menuju masyarakat modern dan faktor utamanya dalam modrenisasi adalah berkembangnya ilmu pengetahuan dan teknologi dalam masyarakat. Seperti yang dikemukakan oleh Harold Rosenberg dalam Koentjaraningrat modernisasi adalah sebuah tradisi baru yang mengacu pada urbanisasi atau hingga sejauh mana dan bagaimana pengikisan sifat-sifat pedesaan suatu kelompok masyarakat terjadi.

Pengelolaan sebuah tim musik di gereja dalam peribadatan merupakan sebuah upaya dari menanamkan nilai-nilai modernisasi dan globalisasi. Seringkali sebuah organisasi musik yang berusaha mengikuti perkembangan zaman mendapatkan penilaian negatif dari beberapa kalangan masyarakat, karna dianggap tidak sesuai dengan tatanan gereja.
Beberapa kalangan masyarakat kristiani masih berfikir secara konvensional dalam pengelolaan organisasi pelayanan musiknya, sehinggah terkadang berakibat pada hilangnya ide-ide baru dalam keberlangsungan fungsi tim musik dalam tugasnya sebagai mediator pada peribadatan-peribadatan kristiani. Kurangnya pengetahuan dalam pengelolaan tim musik menjadi alasan untuk meningkatkan kualitas pelayanan musik dan menghindari hilangnya regenerasi. Kondisi pengelolaan musik diluar gereja yang lebih baik menjadi alasan beberapa oknum pemusik gereja untuk memilih berkiprah diluar gereja. Hal ini menjadi problema bagi gereja-gereja terutama yang berada di wilaya perkotaan, ketika gereja itu tidak membenahi pengelolaan musiknya maka akan menjadi gereja yang tertinggal dan tidak sedikit anggota gerejanya yang berpindah ke gereja lain yang notabennya memiliki pengolahan musik lebih baik.

Peneliti melihat bahwa yang ada di Manado memiliki pengelolaan musik yang baik, hal ini dilihat dari kualitas penyajian musik dan bentuk artistik seni lainnya antaralain yaitu: Kostum yang telah disesuaikan dengan tema yang ada, aransemen musik yang tidak monoton, presisi atau perpindahan lagu dengan setiap kegiatan yang dilaksanakan dalam proses peribahdatan sesuai dengan durasi yang telah di sesuikan pada rundown acara, sound yang dihasilkan sesuai 
dengan porsi yang dibutukan jemaat yang mengikuti ibadah baik secara langsung atau secara online.

Keberadaan IFGF Manado menjadi sebuah tantangan bagi Gereja IFGF Manado menghadapi perkembangan zaman terutama dikota Manado serta menjadi gereja yang menumbukan iman jemaat melalui pengelolaan musik yang modern namun tetap dalam kaidah pelayanan musik gereja pada umumnya. IFGF Manado memiliki nilai-nilai yang menarik untuk diteliti dalam rangka mencari tahu nilai-nilai pendidikan karakter yang terdapat pada pengelolaan tim IFGF Praise.

Dari fenomena tersebut dapat diidentifikasikan permasalahan yang dapat dibahas dalam penelitian ini adalah nilainilai pendidikan karakter pada pengelolaan musik di IFGF Praise Manado.

Penelitian bertujuan untuk menjelaskan apa saja tahapan pengelolaan musik di IFGF Praise Manado dan untuk menjelaskan penerapan nilainilai pendidikan karakter dalam pengelolaan musik di IFGF Praise Manado.

\section{Metode}

Penelitian ini mengunakan metode kualitatif dengan pendekatan studi kasus dalam pengelolaan tim IFGF Praise Manado. Dalam proses mengungkapkan nilai-nilai Pendidikan karakter yang terdapat dalam pengelolaan tim IFGF
Praise peneliti mengimplementasikan teori manajemen yang dikemukaan George R. Terry dan teori manajemen pertunjukan oleh M.Jazuli. Adapun unsurunsur manajemen yang diteliti adalah perencanaan, pengorganisasian, pelaksanaan dan pengawasan. Sedangkan unsur-unsur manajemen pertunjukan yang menjadi kajian seperti yang dikemukaan oleh Jazuli yaitu Sistem pelembagaan, program pertunjukan, tata kerja produksi, system pembiayaan, pemasaran dan tata kerja penyelenggara. Ada pun lokasi penelitian berada di gereja IFGF Manado khususnya pada tim pelayanan IFGF Praise Manado.

Diasumsikan bahwa adanya nilainilai Pendidikan karakter dalam pengelolaan Pelayanan Musik pada IFGF Praise Manado. Pengelolaan Pelayanan Musik pada IFGF Praise memiliki kesamaan dalam pengelolaan pertunjukan musik pada umumnya.

Untuk memperoleh data-data terkait penelitian ini dilakukan wawancara kepada beberapa narasumber antara lain anggota IFGF Praise Manado dan beberapa anggota The Box (Service Management) IFGF Manado.

\section{Hasil dan Pembahasan}

Hasil penelitian ini merupakan analisis data yang sudah diperoleh melalui observasi dan wawancara mendalam terhadap anggota IFGF Praise dan beberapa orang lainnya di luar anggota 
IFGF Praise. Data-data yang diperoleh merupakan salah satu bentuk perencanaan jangka pendek yang dimiliki oleh tim IFGF Praise Manado. Untuk program jangka menengah dan jangka Panjang belum sempat dikemukakan karena keterbatasan waktu penelitian ini.

Penelitian ini mengkaji nilai-nilai pendidikan karakter yang terdapat dalam pengelolaan pelayanan musik di IFGF Praise Manado. Sesuai dengan kajian teori yang sudah dikemukakan dalam bab sebelumnya bahwa ada tiga nilai pendidikan karakter yang akan diteliti antara lain; pendidikan karakter dalam bidang spiritual, pendidikan dalam bidang kepemimpinan,dan pendidikan karakter dalam bidang sosial.

Asumsi dasar dari penelitian ini adalah adanya nilai-nilai pendidikan karakter (spiritual, kepemimpinan, dan sosial) yang dapat dijelaskan dalam pengelolaan pelayanan musik IFGF Praise di Gereja IFGF Manado.

Dari hasil temuan sudah dikemukakan tentang konsep dasar pengelolaan sebuah organisasi pelayanan musik dari IFGF Praise Manado yaitu; perencanaan, pengorganisasian, penggerakan, dan pengawasan. Konsep dasar pengelolaan tersebut mendasari pengeloaan tim musik IFGF Praise Manado dalam tugasnya di peribadatan gereja IFGF Manado.

Pada masa pandemi ini pelaksanaan peribadatan IFGF Manado dilakukan dalam beberapa bentuk oleh karena harus mengikuti peraturan dari Pemerintah. Pada awal pandemi di tahun 2020 yang lalu kegiatan peribadatan dilaksanakan secara online dan disajikan dalam bentuk rekaman, tapping, dan live streaming. Hal ini seperti yang disampaikan oleh salah satu anggota IFGF Praise bahwa peribadatan IFGF Manado selama pandemi di tahun 2020 dilaksanakan secara online, mulai dari recording selama di studio, tapping masing-masing pemusik dan penyanyi kemudian disatukan menjadi sebuah video yang rapi kemudian ditayangkan di Youtube Chanel IFGF Manado.

Berbeda dengan tahun 2021 bahwa peribadatan IFGF Manado diadakan secara Onsite di gedung gereja dengan kapasitas jemaat $50 \%$ dan ditayangkan di Youtube Chanel IFGF Manado dan Live Streaming di akun Facebook IFGF Manado. Ada perbedaan cara penyajian peribadatan IFGF Manado sebelum masa Pandemi dan pada saat masa pandemi.

Namun demikian pengelolaan pada pelayanan musik IFGF Praise Manado tidak terjadi perubahan yang sangat signifikan. Untuk pelaksanaan peribadatan IFGF Mando yang melibatkan tim musik IFGF Praise maka tim IFGF Praise mengadakan sebuah "aturan main" yang berbeda dari tahun-tahun sebelumnya. Jika di tahun-tahun sebelumnya IFGF Praise dalam pelayanan Ibadah melibatkan banyak anggota yang terlibat 
khusunya di hari Minggu, dengan personil yang bervariasi dan kapasitas orang yang cukup banyak, saat ini para pelayan di Ibadah IFGF Manado dibatasi dan pemanfaatan tim yang tetap (selama pandemi) dengan mengikuti protokol kesehatan.

Satu hal yang menarik bahwa kegiatan peribadatan IFGF Manado merupakan sinergi antara tim IFGF Praise dan Tim The Box. Dua tim inilah yang berperan dalam acara peribatadan (Ibadah Raya) dari awal sampai akhir peribadatan.

Jika dilihat dari tata cara peribadatan IFGF Manado maka dapat dijelaskan peran dan fungsi masingmasing tim (IFGF Praise dan The Box). Di bawah ini ada contoh tata ibadah peribadatan IFGF Manado dalam bentuk timeline.

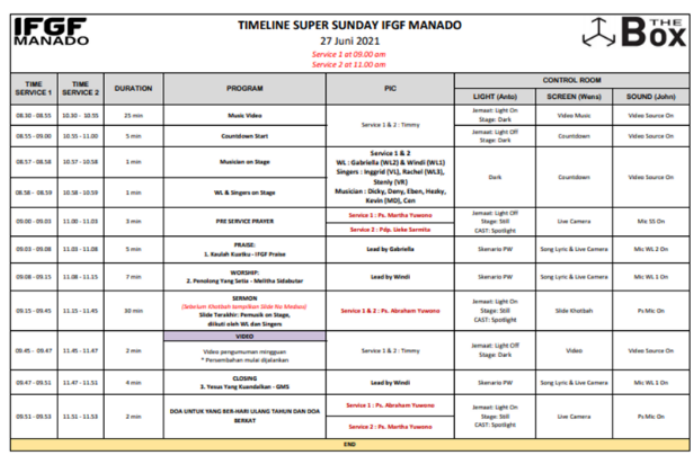

Dari timeline di atas dapat dijelaskan sebagai berikut :

1. Breafing dilakukan oleh HOD The Box ataupun orang yang mewakili

2. Adanya peran The Box dalam mempersiapkan Time Line yang dibagikan kepada semua anggota yang bertugas di hari itu.
3. The Box akan mengatur jalannya peribadatan sejak awal

4. Tim IFGF Praise naik panggung dan memainkan serta menyanyikan beberapa lagu (Lagu Praise dan Lagu Worship)

5. Pengkhotbah naik panggung untuk menyampaikan Firman Tuhan, saat ini tim IFGF Praise duduk di tempat yang sudah disediakan oleh tim The Box.

6. Setelah Khotbah Tim IFGF Praise naik panggung lagi untuk memainkan lagu penutup

7. Evaluasi dilakukan oleh Pastor dibidang Super Sunday dan Generation

Pengelolaan pelayanan Musik di IFGF Manado merupakan kolaborasi antara tim IFGF Praise dan Tim The Box. Aspek-aspek manajemen pertunjukan menjadi bagian dalam penyajian peribadatan (Ibadah Raya).

\section{Pendidikan Karakter dalam Pegelolaan Pelayanan Musik IFGF Praise}

Dari data-data yang sudah diperoleh melalui observasi dan wawancara maka dapat dijelaskan bahwa adanya pendidikan karakter dalam pengelolaan pelayanan musik di IFGF Praise Manado.

\section{Pendidikan Karakter Spiritualitas}

Pendidikan karakter spiritualitas dalam hal ini adalah spiritualitas Kristiani yang diperoleh dari pengelolaan pelayanan musik IFGF Praise Manado.

Melalui wawancara dari beberapa anggota IFGF Praise dan The Box IFGF 
Manado dan dengan aspek-aspek spiritualitas yang menjadi pedoman dalam wawancara maka diperoleh hasil analisis sebagai berikut :

a) Pertanyaan diajukan untuk mengetahui tentang saat teduh pribadi dan membaca Alkitab setiap hari.

"Saat teduh pribadi Anda dilakukan setiap jam berapa setiap harinya ?" Bagi HOD IFGF Praise (Dicky Kairupan) bahwa membiasakan diri dengan saat teduh setiap hari akan memiliki spiritulaitas yang baik. Menurutnya bahwa setiap anggota IFGF Praise harus memiliki waktu saat teduh agar pada saat melakukan pelayanan di gereja dapat memberikan teladan bagi jemaat yang hadir karena anggota IFGF Praise dapat memberi dampak secara spiritualitas.

b) Pertanyaan berikutnya adalah tentang keterlibatan anggota IFGF Praise maupun The Box dalam kegiatan selama satu minggu berjalan selain ibadah Raya di hari minggu.

"Selain ibadah raya, kegiatan apa yang Anda ikuti sepanjang minggu ?"

Sebagai seorang pelayan di gereja IFGF Manado sudah menjadi standar bagi mereka untuk tergantung dalam kegiatan lainnya selain peribadatan minggu. Hal ini seperti yang disampaikan oleh Pastor Abraham bahwa untuk meningkatkan pemahaman firman dan persekutuan dengan jemaat lainnya, maka jemaat IFGF
Manado harus mengikuti salah satu kegiatan lainnya selain ibadah raya setiap hari minggu. Adapun acara-acara lain yang dapat diikuti adalah; iCare, IFGF Man, IFGF Woman, Doa Malam setiap Selasa.

c) Pertanyaan berikutnya adalah untuk mengetahui seberapa besar tingkat kebergantungan anggota IFGF Praise dan The Box dalam mengandalkan Tuhan dalam hidupnya.

"Jika ada masalah yang besar dalam hidup Anda, apa yang Anda lakukan ?"

Hampir semua narasumber memberikan tanggapannya bahwa mereka memiliki kehidupan doa yang baik, hal ini dibuktikan dengan pernyataan mereka dalam menanggapi jika ada persoalan besar dalam hidup mereka, ada usaha untuk melakukan doa pribadi dan menyerahkan persoalan di hadapan Tuhan. Seperti yang dikemukakan oleh koordinator Multimedia (Wens Rumengan) dalam wawancaranya bahwa doa merupakan nafas hidup pelayan Tuhan, apalagi sudah dipercaya pelayanan di IFGF Manado artinya ada tanggung jawab meningkatkan spiritualitas melalui kehidupan doa.

d) Pertanyaan berikutnya terkait dengan dampak pelayanan yang dilakukan terhadap tanggapan jemaat melalui sikap dan perilaku selama melakukan pelayanan di panggung di hari Minggu. 
"Bagaimana caranya agar jemaat bisa merasakan ada keseriusan pelayanan IFGF Praise saat peribadatan?"

Keseriusan dalam melakukan pelayanan sangat berdampak pada jemaat saat Tim IFGF Praise melakukan tugasnya dalam peribadatan Minggu. Sikap yang baik yang harus dimiliki adalah ketulusan dan tindakan yang positif dalam setiap melakukan pelayanan dalam ibadah.

Seperti yang dikemukakan oleh salah satu Worship Leader (WL) yang cukup senior di kalangan IFGF Manado, menurut dia bahwa sikap yang sifatnya mensupport jemaat dalam pujian dan penyembahan merupakan hasil dari perenungan pribadi sebelum melaksanakan pelayanan.

\section{Pendidikan}

Karakter

Kepemimpinan

Adanya pengelolaan Pelayanan Musik IFGF Praise yang begitu rapi dan terencana dengan baik ternyata dapat memunculkan karakter-karakter kepemimpinan bagi setiap anggotanya. Hal ini sejalan dengan pemikiran Kutha Ratna dalam bukunya tentang Karya Seni dalam Pendidikan Karakter, dikatakan bahwa karya seni mampu menumbuhkan karakter-karakter kepemimpinan karena di dalam penyajian karya seni selalu melibatkan banyak orang dan penyatuan ide-ide, dengan demikian adanya pendelegasian dan pembagian tugas yang baik dan terstruktur sehingga penyajian karya seni dapat dinikmati oleh penikmatnya.

Seringkali sebuah kelompok pelayanan saling menunggu jika pemimpin tidak menginstruksikan untuk melakukan sesuatu. Biasanya IFGF Praise setelah melaksanakan tugasnya dalam peribadatan ada kegiatan evaluasi yang dipimpin oleh HOD. Namun bagaimana jika HOD tidak mengajak untuk evaluasi apakah masih ada orang yang memiliki tindakan untuk melakukan evaluasi. Menurut para anggota IFGF Praise perah terjadi hal semacam itu, namun akhirya tidak ada pembicaraan lebih lanjut. Berbeda dengan sekarang saat ada penataan dan pengelolaan lebih baik, masng-masing anggota memiliki kerinduan selalu ada evaluasi dari setiap selesai melaksanakan pelayanan. Seringkali inisiatif hanya muncul dari pemimpin, namun dengan adanya penhgelolaan lebih baik ternyata menanamkan bagi anggota untuk memiliki inisiatif dalam kemajuan tim, baik tim IFG Praise maupun The Box.

3. Pendidikan Karakter Peduli Sosial (Jiwa Sosial/ Moralitas)

Pengeloalan pelayanan musik IFGF Praise Manado berdampak juga pada meningkatnya jiwa sosial dari masing-masing anggota, baik IFGF Praise maupun The Box. Kutha Ratna mengemukakan bahwa karakter-karakter dalam karya seni seringkali muncul dalam sikap seniman untuk memiliki jiwa yang peduli dengan sosial. Adanya kepedulian 
sosial yang tinggi ketika menjadi pelakupelaku seni.

Seringkali kesalahan sepele
memicu terjadinya perkelahian dengan
sesama anggota tim. Berbeda dengan
mereka yang melayani di bidang peribadatan, adanya tingkat kepedulian untuk menjaga stabilitas sosial sangat tinggi. Hal ini dapat terjadi ketika anggota tim menyadari bahwa mereka dalam sebuah tim yang melakukan pelayanan di bidang kerohanian, bukan pada tim-tim musik pada umumnya yang tidak mempedulikan stabilitas sosial.

Dengan adanya pengelolaan yang baik serta terstruktur maka menimimalisir terjadinya perselihan antar anggota tim IFGF praise dan The Box. Seperti yang dikemukakan oleh Inggrid seorang Singer di IFGF Praise Manado, menurut dia bahwa seringkali ada beberapa orang sengaja ingin mengadudomba agar terjadi perselisihan, namun dihadapi dengan pola pikir dewasa dan kerendahan hati. Tidak perlu menanggapi dengan hati yang panas, tetapi harus memiliki hati yang mulia.

Begitu juga di dalam tim The Box, seringkali ada beberapa anggota yang berselisih paham namun mereka memilih untuk berdamai dengan keadaan. Mencari solusi bersama-sama adalah jalan keluar bagi persoalan-persoalan yang terjadi. Dian seorang anggota The Box berpendapat bahwa lebih memilih damai dan memiliki hati yang mulia daripada menanggapi perkelahian atau perselisihan. Menurut dia jika ada perselisihan secepatnya diselesaikan, perlu disadari bahwa sesuatu yang dikerjakan merupakan tanggung jawab dalam peribadatan.

Kerendahan hati dan sikap peduli sosial seringkali susah didapatkan dalam realita kehidupan, karena hanya orangorang yang mau merendahkan hati yang mau bersikap seperti itu. Seringkali sebuah teguran dan masukan dianggap sebagai suatu kritikan yang menyakitkan, namun sebenarnya itu adalah bentuk kepedulian pemimpin terhadap anggota lainnya. Yohana salah satu anggota The Box mengemukakan bahwa dia sering mendapat teguran dari koordinatornya (stage manager) pada saat melaksanakan pelayanannya, karena ada beberapa hal kesalahan yang sering dia lakukan. Namun bagi dia, teguran itu adalah sebuah masukan yang baik dan motivasi untuk bertindak hati-hati.

Sense of belonging yang artiya rasa memiliki yang besar, merupakan katakata yang sering dilontarkan oleh Senior Pastor IFGF Manado Ps. Abraham Yuwono dalam pertemuan evaluasi maupun dalam pertemuan-pertemuan dengan anggota tim lainnya. Menurut dia bahwa rasa memiliki terhadap tim akan berdampak pada tingginya rasa kepedulian sesama termasuk menyayangi sarana dan prasarana. 
Di lingkungan tim IFGF Praise pernah terjadi seorang operator Sound Sistem mendapat teguran dari pemusik dari panggung menggunakan alat komunikasi ear phone, namun berujung rasa sakit hati pada operator sound system. Tetapi sekarang orang tersebut sudah tidak tergabung lagi dalam tim IFGF Praise Manado.

Turunnya kehidupan rohani seseorang maka akan berakibat pada turunnya moralitas seseorang, hal ini diungkapkan oleh Markus Wibowo dalam wawancara. Menurut dia bahwa sebagai anggota pelayanan di tim IFGF Praise dan The Box sudah menjadi keharusan memiliki kehidupan rohani yang baik agar moralitasnya juga baik. Jangan hanya mengandalkan kemampuan saja namun tidak mempedulikan moralitasnya.

Pada praktiknya para pemusik dan penyanyi dan bahkan seluruh anggota tim baik dari IFGF Praise dan The Box selalu diarahkan oleh Stage Manager yang bertugas saat itu. Menghargai arahan tersebut merupakan bentuk implementasi dari adanya kepedulian sosial yang tinggi. Eben Ratela seorang pemusik IFGF Praise Manado mengemukakan bahwa dia sendiri tidak merasa risih jika yang mengarahkan ternyata umurnya jauh di bawah dia, apapun yang menjadi arahan dari stage manager dia akan selalu tunduk, misalnya sudah saatnya naik stage, ditegur karena sikap di panggung yang kurang sopan dan lain sebagainya.
Tergabungnya anggota IFGF Praise dalam tim berdampak pada pola pertemanan dengan orang lain baik di gereja maupun di luar gereja. Ada satu sikap yang baik terjadi dalam diri anggota IFGF Praise, mereka memiliki kemurahan hati dan kerendahan hati oleh karena itu semakin disukai oleh banyak orang. Feibe Rumondor seorang WL dan Singer dan sekaligus dia adalah seorang guru di salah satu Sekolah Swasta di Manado menjelaskan bahwa adanya sikap yang murah hati dan sikap menerima ketika diproses dalam tim ini. Tim ini mengajarkan banyak hal bagaimana seseorang harus bertindak dan berperilaku. Oleh karena dalam satu tim, maka sikap kerjasama dan menjalin relasi itu penting dan melatih untuk menjadi pribadi yang peduli sosial dan lingkungan.

Melihat anggota tim lain yang masih "amatiran" terkadang menimbulkan rasa iba dan belas kasihan ingin membantunya agar mengalami kenaikan level. Demikian juga halnya dalam pelayanan IFGF Praise, beberapa anggota yang sudah merasa senior dan memiliki skill lebih baik, mereka mengambil waktu dalam memberi pelatihan kepada yang junior atau yang skillnya masih di bawah standar. Hal ini seperti yang dilakukan oleh IFGF Praise dalam upaya memberikan training skill kepada anggota yang masih junior, HOD dengan rela memberikan pelatihan secara gratis kepada anggota yang junior. Menurut dia bahwa memberi 
pelatihan kepada junior adalah penting karena untuk mempersiapkan regenerasi.

Salah satu bentuk kepedulian sosial adalah dengan memberikan bantuan kepada sesama anggota IFGF Praise baik secara materi maupun secara moral. Cthleen atau biasa disapa dengan nama Cecen seorang pemusik juior namun memilki bakat yang sangat bagus dalam memainkan instrumen Drum, dia merasa bahwa kepedulian kakak senior terhadap dia sangat tinggi, bahkan dia sendiri merasa bahwa bisa bermain dan melakukan pelayanan saat ini oleh karena ada training-tarining yang dilakukan oleh kakak senior. Menurut dia sebaiknya training dilakukan setiap tahun untuk meningkatkan skill dan menambah personil. Begitu juga dengan Danu Krisna seorang anggota Stage Manager memberikan keterangan bahwa dia merasa dibimbing oleh kakak senior di tim The Box untuk mempersiapkan segala yang diperlukan pada saat melaksanakan tugasnya di ibadah raya IFGF Manado.

Kepedulian sosial yang dimiliki oleh anggota baik IFGF Praise maupun The Box terbentuk saat menyadari betapa pentingnya bekerja bersama-sama dan melakukan tanggung jawab pelayanan bersama-sama saling sinergi dan saling melengkapi. Dengan demikian pengelolaan peyanan musik di IFGF Praise mampu memunculkan nilai-nilai pembentukan karakter dalam hal kepedulian sosial. Meskipun prosesnya panjang namun membawa hasil yang baik dan ada buah-buah yang diperoleh dari setiap usaha keras anggota IFGF Praise dan The Box.

\section{Kesimpulan}

Dari semua pemaparan data dan hasil penelitian yang telah dilakukan maka dapat diambil kesimpulan bahwa :

1. Keberhasilan Tim IFGF Praise Manado dalam pelayanan musiknya merupakan sinergi dengan tim lain yang memiliki istilah lokalnya adalah tim The Box ini memiliki peran yang penting dalam pelaksanaan peribadatan di gereja IFGF Manado, karena The Box adalah sebuah "tim sukses" dalam tata ibadah gereja IFGF Manado.

2. Peribadatan di Gereja IFGF Manado melibatkan tim IFGF Praise dan Tim The Box yang dalam sebuah tatanan organisasi memiliki peran penting dalam peribadatan gereja IFGF Manado. Dengan istilah Super Sunday Service gereja IFGF Manado mengelola pelayanan musiknya dengan baik dan terstruktur, walaupun masih ada juga hal-hal yang harus dibenahi dan dievaluasi.

3. Pelayanan musik Gereja yang dikelola dengan baik dan terstruktur akan berdampak pada penyajian musik dan penataan peribadatan yang rapi dan dinamis sehingga mampu menjadi kajian menarik untuk diteliti dari perspektif seni pertunjukan dan penataannya. Konsep dasar pengelolaan pelayanan musik IFGF 
Praise Manado adalah; perencanaan, pengorganisasian, penggerakan, dan pengawasan.

4. Adapun nilai-nilai yang diperoleh dari pengelolaan pelayanan musik IFGF Praise Manado adalah adanya nilai-nilai Pendidikan Karakter Kristiani. Nilai-nilai pedidikan karakter tersebut adalah; pendidikan karakter kepemimpinan, pendidikan karakter spiritualitas, dan pendidikan karakter peduli sosial yang masing-masing karakteristik dapat terlihat dari setiap perilaku anggota masingmasing tim, baik pada tim IFGF Praise maupun tim The Box.

\section{Kepustakaan}

Abu Ahmadi dan Nur Uhbiyati. IImu Pendidikan. Jakarta: Rineka Cipta, 2001.

Afrizal. (2014). Metode Penelitian Kualitatif. Jakarta: Rajawali Pers

Afwa Astitisar. El Mughny. Manajemen Pagelaran Seni Pertunjukan Pada Kegiatan Pada Kegiatan Di SMA N 1 Kedungwuni Kabupaten Pekalongan. Skripsi. Prodi Sendra Tasik Universitas Negeri Semarang, 2017.

Alister E McGrath, Spiritualitas Kristen. Penerbit Bina Media Perintis Medan, 2007

Arif Rohman. Memahami Pendidikan dan IImu Pendidikan. Yogyakarta, 2009.

Buchori Alma. Pembelajaran Studi Sosial. Bandung: Alfabeta. 2010

Darmiyati Zuchdi. Pendidikan Karakter dalam Perspektif Teori dan
Praktik.rev.ed. Yogyakarta: UNY Press, 2011.

Delamont Vic, The Ministry Of Music In The Church. Chicago: Moody Press, 1980.

Elly M. Setiadi, Kama A. Hakam, Ridwan Effendi. Ilmu Sosial dan Budaya Dasar. Jakarta: Kencana, 2012.

Fuad Ihsan. Dasar-Dasar Kependidikan. Jakarta: Rineka Cipta

Gans George, Ignatius of Loyola: Exercises and Selected Works, New York: Paulist 1991.

George R. Terry. Dasar-Dasar Manajemen. Jakarta: Bumi Aksara, 1999.

Hani Handoko. Manajemen. Yogyakarta: BPFEE Yogyakarta, 1999.

Harnani Santi. Unsur-unsur dramatik dan nilai pendidikan dalam film Denias. Skripsi Universitas Sebelas Maret, Surakarta. 2012.

Hera Lestari Malik, Agus Taufik \& Puji Lestari Prianti. Pendidikan Anak SD. Jakarta: Universitas Terbuka. 2008

Jane Stuart Smith. Karunia Musik, Jakarta. 2001.

Jazuli.M. Manajemen Seni Pertunjukan. Yogyakarta: Graha IImu, 2014.

Kementerian Pendidikan Nasional. Pedoman Pelaksanaan Pendidikan Karakter. Jakarta: Pusat Kurikulum dan Perbukuan. 2011.

Lovelace \& Rice, Music And Worship In Church. USA: Abingdon Press 1976.

Malayu SP. Hasibuan. Manajemen: Dasar, Pengertian dan Masalah. Edisi revisi. Jakarta: PT Bumi Aksara. 2001.

Mark A. Mclntosh. Christology from Within. Spirituality and the Incarnation in Hans Urs von Balthasar. Notre dame 
\& London: University of Notre Dame Press, 1996. p.ix.

Mawene. Gereja Yang Bernyayi: Menghidupkan Ibadah Dengan Lagu. Yogyakarta: ANDY, 2004.

Mike \& Hibert. Pelayanan Musik. Yogyakarta: Andi, 2006.

Murgianto, S. Manajemen Pertunjukan. Jakarta: Departemen Pendidikan dan Kebudayaan. 1985.

Murni. Tari dan Manajemen Pertunjukan. Jakarta: Garak Jo Garik. 2013.

Puhl, Louis S.J, The Spiritual Exercise of St. Ignatius, Based on studies in the Languages of the Autograph , Chicago: Loyola University Press, 1991.

Quentin J. Schultae, Ibadah Hi-tech. Singapore: Singapore Bible College, 2006.

Rahmat, P. S. Penelitian kualitatif. Equilibrium, 5(9), 2009.

Ratna, Kutha. Peranan Karya Sastra, Seni, dan Budaya Dalam Pendidikan Karakter. Yogyakarta : Pustaka Pelajar. 2014

Rosenberg, Harold. Dalam Koentjaraningrat. Pengantar IImu Antropologi. Jakarta: PT Rineka Cipta, 2009

Serafim A. Harikusuma. Manajemen Strategi Paduan Suara Di SMA Kristen Eben Haezer Manado. Skripsi 2018.

Sugiyono. Metode Penelitian Kuantitatif, Kualitatif, dan $R$ \& D. Bandung: Alfa Beta, 2016.

Sugiyono. Metode Penelitian Pendidikan Pendekatan kuantitatif kualitatif $R$ \& D. Bandung: Alfabeta. 2014.
Sukardi. Pendidikan Budi Pekerti Dalam Dongengan Sulawesi Selatan. Jakarta: Bale Pustaka, 1997.

Sulhan, Najib. Pengembangan Karakter Dan Budaya Bangsa. Surabaya: Jaring Pena, 2010.

Tim Penyusun. Panduan Pelayanan IFGF Praise. Jakarta: IFGF Praise Global, 2020.

Victor, I. Tanja, Spiritualitas, Pluralitas dan Pembangunan di Indonesia, PT BPK Gunung Mulia, 2005.

Wibowo, Markus. "Peranan Musik Gereja Dalam Pembentukan Karakter Jemaat Dan Pembawa Misi Gereja di Gereja Bethany Indonesia Menara Doa Melonguane." JURNAL PSALMOZ 1.1 (2020): 1-14.

Yu Qi Nian, Pelayanan Musik Gereja, Hongkong: Fu Ing Zhen Zhu. 1985. 